\title{
Human Coronavirus HCoV-229E Enters Susceptible Cells via the Endocytic Pathway
}

\author{
DIANNA M. BLAU AND KATHRYN V. HOLMES \\ University of Colorado Health Sciences Center, Department of Microbiology, 4200 E 9th \\ Avenue, Denver, CO, 80262, USA
}

\section{INTRODUCTION}

Human coronaviruses $(\mathrm{HCoV})$ are important causes of upper respiratory infections in humans of all ages. In addition, $\mathrm{HCoVs}$ have occasionally been associated with pneumonia, meningitis and diarrhea. HCoV RNA has been detected by RT-PCR in up to $40 \%$ of adult human brains (Stewart et al., 1992). There are two serotypes of $\mathrm{HCoV}$ represented by HCoV-229E and $\mathrm{HCoV}-\mathrm{OC} 43$. HCoV-229E is a member of coronavirus serogroup I, which also includes porcine transmissible gastroenteritis virus (TGEV) and feline and canine coronaviruses. The viral attachment protein S of HCoV-229E is unlike S proteins of many coronaviruses in serogroup II, in that it is not cleaved during virus assembly, nor does it cause syncytia formation.

In order to infect susceptible cells, the S glycoprotein of HCoV-229E binds to its receptor, human aminopeptidase $\mathrm{N}(\mathrm{hAPN})$ also known as CD13, a metalloprotease (Yeager et al., 1992). hAPN is expressed on a variety of cells including monocytes, granulocytes, neuronal cells and the apical surface of renal, lung and intestinal epithelial cells (Look et al., 1989, Lachance et al. 1998). After attachment of S to hAPN, the viral envelope must fuse with a cellular membrane, either the plasma membrane or an endocytic membrane. Most strains of mouse hepatitis virus (MHV) in serogroup II are believed to gain entry into cells by fusing at the plasma membrane. This is supported by the data that MHV causes cell fusion at neutral or alkaline $\mathrm{pH}$. (Sturman et al., 1990). In addition it has been 
reported that internalization of MHV-A59 by endocytosis does not lead to a productive infection (Kooi et al., 1991). In contrast, porcine transmissible gastroenteritis virus (TGEV), after binding to its receptor, porcine APN (pAPN), is observed by electron microscopy in endocytic pits. TGEV infection is blocked by ammonium chloride or bafilomycin Al, agents that prevent the acidification of endosomes (Hansen et al. 1998). These data suggest that TGEV penetrates at the membrane of an acidic intracellular compartment, although MHV penetrates by fusion at the plasma membrane.

We have studied the entry of $\mathrm{HCoV}-229 \mathrm{E}$ into polarized human colon carcinoma cells (Caco-2) cultured on permeable filters. hAPN is expressed predominantly on the apical surfaces of these cells (LeBivic et al., 1990). In this report we describe the preferential entry of $\mathrm{HCoV}-229 \mathrm{E}$ at the apical surfaces of polarized Caco-2 cells. We also show that the entry of $\mathrm{HCoV}-$ 229E into MRC-5 human lung epithelial cells is inhibited by drugs that block the acidification of endosomes. These findings suggest that $\mathrm{HCoV}-$ $229 \mathrm{E}$ undergoes endocytosis after binding of $\mathrm{S}$ to hAPN at the plasma membrane, and the virion is then sorted into endosomes where fusion of the viral envelope and endocytic membrane occur.

\section{RESULTS}

The primary site of replication of HCoV-229E is in human respiratory epithelial cells. To investigate the entry process of HCoV-229E into susceptible cells in vitro, we first assayed the interaction of virions with the polarized epithelial cells. Caco-2 cells, grown on permeable filters to allow access to apical and basal surfaces, were inoculated with $\mathrm{HCoV}-229 \mathrm{E}$ via either the apical or basal medium, and the amount of virus released into each medium was then determined. Table 1 shows that in polarized Caco- 2 cells, $\mathrm{HCoV}-229 \mathrm{E}$ entered the cells more efficiently from the apical surface than from the basal surface. The virus was released from the polarized cells into both the apical and basal media. The inefficiency of the virus infecting at the basal surface is not due to a physical barrier presented by the filter because nonpolarized MRC-5 cells were effectively infected from either the apical or the basal membrane. Virus was also released from MRC-5 cells into both the apical and basal media. These results indicate that HCoV-229E enters polarized epithelial cells preferentially at the apical membrane.

Table 1. Virus yields released from polarized Caco- 2 cells

\begin{tabular}{ccc}
\hline Inoculation & Apical Medium pfu/ml & Basal Medium pfu/ml \\
\hline Apical & $2.3 \times 10^{7}$ & $2.0 \times 10^{7}$ \\
Basal & $7.0 \times 10^{3}$ & $4.5 \times 10^{4}$ \\
\hline
\end{tabular}


To further investigate the route of entry of $\mathrm{HCoV}-229 \mathrm{E}$ virions into susceptible cells, we treated cells with agents that inhibit the acidification of the endosomes. If $\mathrm{HCoV}-229 \mathrm{E}$ enters by fusing with endocytic membranes, it is likely that these drugs will inhibit infection. Chloroquine, a weak base, and bafilomycin Al, a specific inhibitor of the vacuolar ATP-ase proton pump both block the acidification of endosomes. As seen in Table 2, treatment of MRC-5 cells with these drugs during virus adsorption inhibits viral infection, whereas treatment after viral replication has begun does not reduce the percent of cells expressing $\mathrm{HCoV}-229 \mathrm{E}$ antigen.

Table 2. Percent of cells expressing 229E antigen at $12 \mathrm{hpi}$

\begin{tabular}{ccll}
\hline Treatment & -1 to $1 \mathrm{hpi}$ & 1 to $3 \mathrm{hpi}$ & 8 to $12 \mathrm{hpi}$ \\
\hline None & 100 & 100 & 100 \\
Chloroquine $(50 \mu \mathrm{M})$ & $28 \pm 1.4$ & $98 \pm 0.8$ & $80 \pm 0.9$ \\
Bafilomycin A $(500 \mathrm{nM})$ & $10 \pm 2.3$ & $60 \pm 1.3$ & $90 \pm 1.2$ \\
\hline
\end{tabular}

Coronaviruses acquire their envelopes and bud intracellularly in the intermediate compartment between the rough endoplastic reticulum and the Golgi apparatus (Tooze et al., 1984). Virions are then transported in vesicles to the plasma membrane and released by exocytosis (Tooze et al., 1987). It is thus possible that chloroquine and bafilomycin Al affect not only the entry but also the release of the virus. Viral yields were compared from cells incubated with drugs either before virus inoculation or at a later time when virus is starting to be released (Figure 1). Incubation in chloroquine or bafilomycin Al before and during virus inoculation resulted in a decrease in viral titers when compared to untreated, inoculated cells. In contrast, when these drugs were added 8-12 hours post inoculation, there was no significant decrease in viral yields compared to untreated, inoculated cells. These results show that the lysosomotrophic drugs inhibit early at virus entry but at later times do not affect the release of virus.

Nocodazole, a microtubule depolymerizing agent, blocks transport from early endosomes to late endosomes in certain cell types (Gruenberg and Howell 1989). To determine if endosomal transport was required for $\mathrm{HCoV}$ $229 \mathrm{E}$ infection, cells were treated during virus adsorption or continuously with nocodazole. Figure 2 shows the growth curves of infectious virus recovered from these and untreated cells. Cells treated with nocodazole yielded lower titers of HCoV-229E than untreated, HCoV-229E infected cells. These results show that microtubule-disrupting drugs inhibit the early stage of virus infection, supporting the hypothesis that $\mathrm{HCoV}-229 \mathrm{E}$ enters cells through the endocytic pathway. 


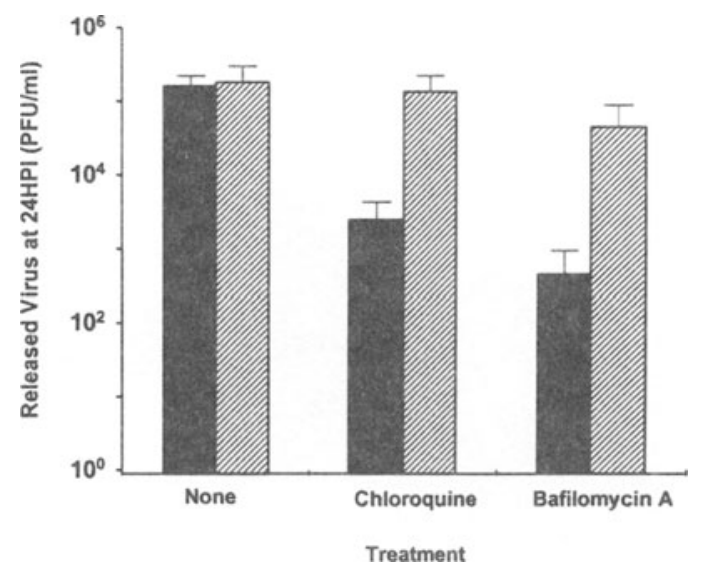

Figure 1. Lysosomotropic drugs inhibited HCoV-229E entry not virus maturation and release. MRC-5 cells were treated at -1 to $1 \mathrm{hpi}$ (solid) or 8-12 hpi (hatched), either with medium alone or with chloroquine $(50 \mu \mathrm{M})$ or bafilomycin $(500 \mathrm{nM})$.

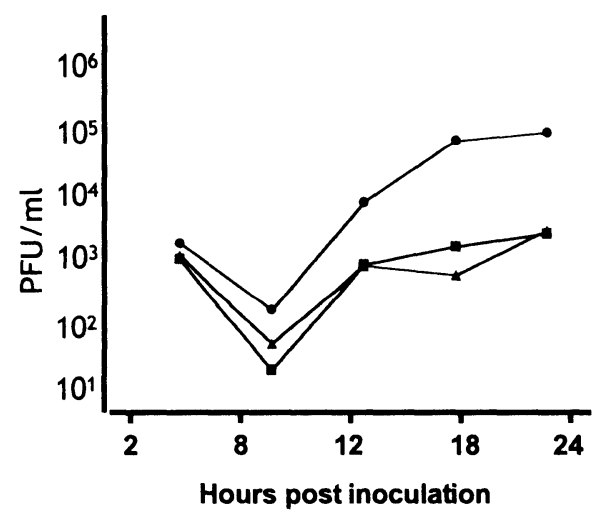

Figure 2. Nocodazole inhibited HCoV-229E infection. MRC-5 cells were treated with medium alone (circles), or nocodazole $6 \mathrm{mg} / \mathrm{ml}$ either from -1 to $3 \mathrm{hpi}$ (squares) or continuously (triangle) from $1 \mathrm{hpi}$ until collection.

\section{DISCUSSION}

In order to establish an infection, $\mathrm{HCoV}-229 \mathrm{E}$ must bind to a specific cell receptor, penetrate by fusion of the viral envelope with the cellular membrane and release its plus strand RNA genome to the cytoplasm. We previously showed that HCoV-229E uses hAPN as its cellular receptor 
(Yeager et al., 1992). We have further investigated the entry process by determining the site of penetration of the virus. We used the Caco-2 cell line, which is a well-characterized human polarized epithelial cell line. The receptor, hAPN, is found predominately on the apical surface (LeBivic et al., 1990) and this correlates with the results presented here that HCoV-229E enters preferentially from the apical surface of these cells. Similar results were also observed when differentiated human airway epithelia were inoculated with HCoV-229E (Wang et al., 2000).

We also investigated the site of penetration of HCoV-229E in MRC-5 cells. Drugs that block the acidification of endosomes inhibited infection of cells by $\mathrm{HCoV}-229 \mathrm{E}$. Influenza virus is a well-characterized enveloped virus that initiates infection by endocytosis. Influenza hemagglutinin (HA), its viral attachment protein, undergoes a conformational change at the low $\mathrm{pH}$ found in endosomes (for review Hernandez et al., 1996). This change in HA allows fusion of the viral envelope with the endosomal membrane to occur. HA glycoprotein is cleaved during virus maturation and is found on the virion envelope as two subunits HA1 and HA2. Unlike influenza, $\mathrm{HCoV}-229 \mathrm{E} \mathrm{S}$ glycoprotein is not proteolytically cleaved. Incubation of $\mathrm{HCoV}-229 \mathrm{E}$ at low $\mathrm{pH}$ alone does not induce observable conformational changes in $\mathrm{HCoV}-229 \mathrm{E}$ S glycoprotein assayed by protease sensitivity and association with liposomes (data not shown). This correlates with the data that treatment of $\mathrm{HCoV}-229 \mathrm{E}$ virions at low $\mathrm{pH}$ alone does not neutralize the virus (Lamarre and Talbot, 1989, personal unpublished data). Similarly TGEV, which also enters through an endocytic pathway, retains its infectivity at low $\mathrm{pH}$ treatment (Laude et al., 1981). It may be that a conformational change occurs that is readily reversible. Another possibility is that viral infectivity requires incubation at low $\mathrm{pH}$ and with the receptor or another cofactor in order to undergo changes that are required for penetration of the virus to occur. Further work characterizing the steps needed for HCoV-229E entry will be valuable as it appears that this virus is using another route and mechanism of entry when compared to the better characterized coronavirus, MHV.

\section{ACKNOWLEDGEMENTS}

We thank Bruce Zelus for critical review of the manuscript. This work was supported by research grant AI26075 and T32 AI07537 (D.B.) from the National Institutes of Health. 


\section{REFERENCES}

Hansen, G. H., Delmas, B., Besnardeau, L., Vogel, L. K., Laude, H., Sjostrom, H., and Noren, O., 1998, The coronavirus transmissible gastroenteritis virus causes infection after receptor-mediated endocytosis and acid-dependent fusion with an intracellular compartment. J. Virol. 72:527-534.

Hernandez, L. D., Hoffman, L. R., Wolfsberg, T. G., and White, J. M., 1996, Virus-cell and cell-cell fusion. Annu. Rev. Cell Dev. Biol. 12:627-661.

Gruenberg, J., and Howell, K. E., 1989, Membrane traffic in endocytosis: insights from cellfree assays. Annu. Rev. Cell Biol. 5:453-481.

Kooi, C., Cervin, M., and Anderson R., 1991, Differentiation of acid-pH-dependent and nondependent entry pathways for mouse hepatitis virus. Virology. 180:108-119.

Lachance, C., Arbour, N., Cashman, N. R., and Talbot, P. J., 1998, Involvement of aminopeptidase $\mathrm{N}$ (CD13) in infection of human neural cells by human coronavirus $229 \mathrm{E}$. J. Virol. 72:6511-6519.

Lamarre, A., and Talbot, P. J., 1989, Effect of pH and temperature on the infectivity of human coronavirus 229E. Can. J. Microbiol. 35:972-974.

Laude, H., Gelfi, J., and Aynaud, J. M., 1981, In vitro properties of low- and high- passage strains of gastroenteritis coronavirus of swine. Am. J. Vet. Res. 42:447-449.

LeBivic, A., Quaroni, A., Nichols, B., and Rodriguez-Boulan, E., 1990, Biogenic pathways of plasma membrane proteins in Caco-2, a human intestinal epithelial cell line. J. Cell Biol. 111:1351-1361.

Look, A. T., Ashmun, R. A., Shapiro, L. H., and Peiper, S. C., 1989, Human myeloid plasma membrane glycoprotein CD13 (gp150) is identical to aminopeptidase N. J. Clin. Invest. 83:1299-1307.

Stewart, J. N., Mounir, S., and Talbot, P. J., 1992, Human coronavirus gene expression in the brains of multiple sclerosis patients. Virology 191:502-505.

Sturman, L. S., Ricard, C. S., and Holmes, K. V., 1990, Conformational change of the coronavirus peplomer glycoprotein at $\mathrm{pH} 8.0$ and $37^{\circ} \mathrm{C}$ correlates with virus aggregation and virus-induced cell fusion. J. Virol. 64:3042-3050.

Tooze, J., Tooze, S. A., and Fuller, S. D., 1987, Sorting of progeny coronavirus from condensed secretory proteins at the exit from the trans-Golgi network of AtT20 cells. $J$. Cell Biol. 105: 1215-26.

Tooze, J., Tooze, S., and Warren, G., 1984, Replication of coronavirus MHV-A59 in saccells: determination of the first site of budding of progeny virions. Eur. J. Cell Biol. 33:281-293.

Wang, G., Deering, C., Macke, M., Shao, J., Burns, R., Blau, D. M., Holmes, K. V., Davidson, B. L., Perlman, S., and McCray Jr., P. B., 2000, Human coronavirus 229E infects polarized airway epithelia from the apical surface. Submitted to J. Virol.

Yeager, C. L., Ashmun, R. A., Williams, R. K., Cardellichio, C. B., Shapiro, L. H., Look, A. T., and Holmes, K. V., 1992, Human aminopeptidase $\mathrm{N}$ is a receptor for human coronavirus 229E. Nature 357:420-422. 